\title{
S П УПРАВЛЕНИЕ ПРЕДПРИЯТИЕМ
}

Е.В. Бурцева

\section{ОСНОВНЫЕ ПОДХОДЫ К СОВЕРШЕНСТВОВАНИЮ МЕТОДОВ ОЦЕНКИ ФИНАНСОВОЙ УСТОЙЧИВОСТИ ПРОМЫШЛЕННЫХ ПРЕДПРИЯТИЙ В УСЛОВИЯХ НЕСТАБИЛЬНОСТИ}

Аннотация: В статье раскрывается сущность и значение оценки финансовой устойчивости промышленных предприятий в условиях нестабильности. Особое внимание уделяется совершенствованию методов оценки финансовой устойчивости.

Оиенка финансовой устойчивости позволяет внешним субъектам анализа определить финансовые возможности организации на длительные перспективы.

Наиболее иелесообразно установить критерии оценки на основе изучения структуры текуших активов предприятий и определения их средних значений.

Ключевые слова: финансовая устойчивость, условия нестабильности, совершенствование методов оценки, промышленное предприятие, финансовое состояние.

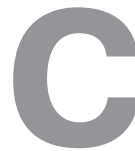

ущностью оценки финансовой устойчивости является оценка обеспеченности запасов и затрат источниками формирования. Степень финансовой устойчивости есть причина определенной степени платежеспособности организации. Наиболее обобщающим показателем финансовой устойчивости является излишек или недостаток источников формирования запасов и затрат.

Оценка финансовой устойчивости позволяет внешним субъектам анализа определить финансовые возможности организации на длительные перспективы ${ }^{1}$.

\footnotetext{
${ }^{1}$ Аверина, О.И. Анализ финансовой устойчивости предприятия по принципам РСБУ и МСФО / О.И. Аверина, И.С. Мамоева // Экономический анализ: теория и практика. - 2009. - №34. - С. 36-44.
}

Цель оиенки финансовой устойчивости - оценить способность предприятия погашать свои обязательства и сохранять права владения предприятием в долгосрочной перспективе. При этом необходимо решить следующие задачи:

- объективная оценка финансовой устойчивости;

- определение факторов, воздействующих на финансовую устойчивость;

- разработка вариантов конкретных управленческих решений, направленных на укрепление финансовой устойчивости ${ }^{2}$.

\footnotetext{
2 Ахметзянова, Д.Г. Влияние некоторых элементов учетной политики на показатели финансовой устойчивости хозяйствующего субъекта / Д.Г. Ахметзянова // Экономический вестник РТ. - 2009. - №2. - С. 28-31.
} 
Значение оценки финансовой устойчивости отдельных хозяйствующих субъектов для экономики и общества в целом слагается из его значения для каждого отдельного элемента этой системы:

- для государства в лице налоговых и других органов аналогичного назначения - своевременная и полная уплата всех налогов и сборов в бюджеты различных уровней. От этого зависит использование доходной части бюджета, а также возможность в полной мере реализовать свои функции и выполнить обязательства, что, в конечном счете, может привести к разным негативным последствиям на государственном и региональном уровнях;

- для внебюджетных фондов, образующихся под эгидой государства, своевременное и полное погашение задолженности по отчислениям в данные фонды. Невыполнение предприятиями своих обязательств влечет нарушения в их работе, в частности в области выплат пенсий, пособий по уходу за детьми, пособий по безработице и т.д.;

- для работников предприятия и прочих заинтересованных лиц - своевременная выплата заработной платы, обеспечение дополнительных рабочих мест. Кроме того, увеличение доходов предприятия приводит к увеличению фондов потребления, а значит, и к улучшению материального благополучия работников данного предприятия;

- для поставщиков и подрядчиков своевременное и полное выполнение обязательств. Для них эти моменты чрезвычайно важны, так как их доход от основной деятельности формируется из поступлений со стороны покупателей и заказчиков. Изъятие финансовых ресурсов из оборота из-за несвоевременности расчетов ослабляет их финансовое состояние, заставляет для обеспечения нормального функционирования привлекать дополнительные заемные средства, что связано с дополнительными расходами;

- для обслуживающих коммерческих банков - своевременное и полное выполнение обязательств согласно условиям кредитного договора. Невыполнение его условий, неплатежи по выданным ссудам могут привести к сбоям в функционировании банков;

- для собственников - доходность, величина прибыли, направляемой на выплату дивидендов. Для владельцев предприятия значение финансовой устойчивости проявляется как фактор, определяющий его прибыльность и стабильность в будущем;

- для инвесторов (в том числе и потенциальных) - выгодность и степень риска вложений в предприятие. Чем оно устойчивее в финансовом отношении, тем менее рискованны и более выгодны инвестиции в него ${ }^{3}$.

Высшей формой устойчивости предприятия является его способность развиваться. Для этого предприятие должно обладать гибкой структурой финансовых ресурсов и возможностью при необходимости привлекать заемные средства, т.е. быть кредитоспособным.

Неустойчивое финансовое положение может наблюдаться как у предприятий,

\footnotetext{
${ }^{3}$ Аверина, О.И. Анализ финансовой устойчивости предприятия по принципам РСБУ и МСФО / О.И. Аверина, И.С. Мамоева // Экономический анализ: теория и практика. - 2009. - №34. - С. 36-44.
} 


\section{Тренды и управление - №1(1) • 2013}

переживающих спад производства и имеющих признаки неплатежеспособности, так и у предприятий, которые, наоборот, отличаются высоким ростом и оборачиваемостью капитала, но имеют высокий уровень условно-постоянных затрат и постепенно теряют прибыль.

Рассмотрев сущность и значение финансовой устойчивости в деятельности предприятия, перейдем к изучению основных подходов оценки финансовой устойчивости предприятия.

Исследования показали, что оценка финансовой устойчивости основывается на коэффициентном методе (относительных показателях). В работе Л.А. Бернстайна указано, что коэффициенты принадлежат к числу самых известных и широко используемых инструментов финансового анализа ${ }^{4}$.

Выделим следующие подходы к оценке финансовой устойчивости организации:

- традиционный;

- $\quad$ ресурсный;

- ресурсно-управленческий;

- основанный на использовании стохастического анализа;

- основанный на использовании теории нечетких множеств;

- основанный на использовании других специальных методов и моделей расчета.

Традиционный, ресурсный и ресурсноуправленческий подходы реализуются в рамках коэффициентного метода.

Традиционный подход. К традиционному отнесем подход, который использует показатели, характеризующие активы организации, источники их формирования и другие стороны финансово-хозяйственной

${ }^{4}$ Бернстайн, Л.А. Анализ финансовой отчетности / Л.А. Бернстайн. - М.: Финансы и статистика, 2002. $-444 \mathrm{c}$. деятельности без группировки по определенному признаку.

В методике показатели платежеспособности и финансовой устойчивости объединены в одну группу, содержащую 10 коэффициентов:

- платежеспособность общая;

- коэффициент задолженности по кредитам банков и займам;

- коэффициент задолженности другим организациям;

- коэффициент задолженности фискальной системе;

- коэффициент внутреннего долга;

- степень платежеспособности по текущим обязательствам;

- $\quad$ коэффициент покрытия текущих обязательств оборотными активами;

- собственный капитал в обороте;

- доля собственного капитала в оборотных средствах;

- коэффициент автономии ${ }^{5}$.

Д.А. Ендовицкий считает, что система комплексного анализа финансовой устойчивости организации должна состоять из четырнадцати блоков ${ }^{6}$ (рис.1).

\footnotetext{
5 Любушин, Н.П. Анализ методов и моделей оценки финансовой устойчивости организаций / Н.П. Любушин // Экономический анализ: теория и практика. - 2010. №1. - C. 3-11.

${ }^{6}$ Ендовицкий, Д.А. Системный подход к анализу финансовой устойчивости коммерческой организации / Д.А. Ендовицкий // Экономический анализ: теория и практика. - 2005. - №6. - С. 7-13.
} 


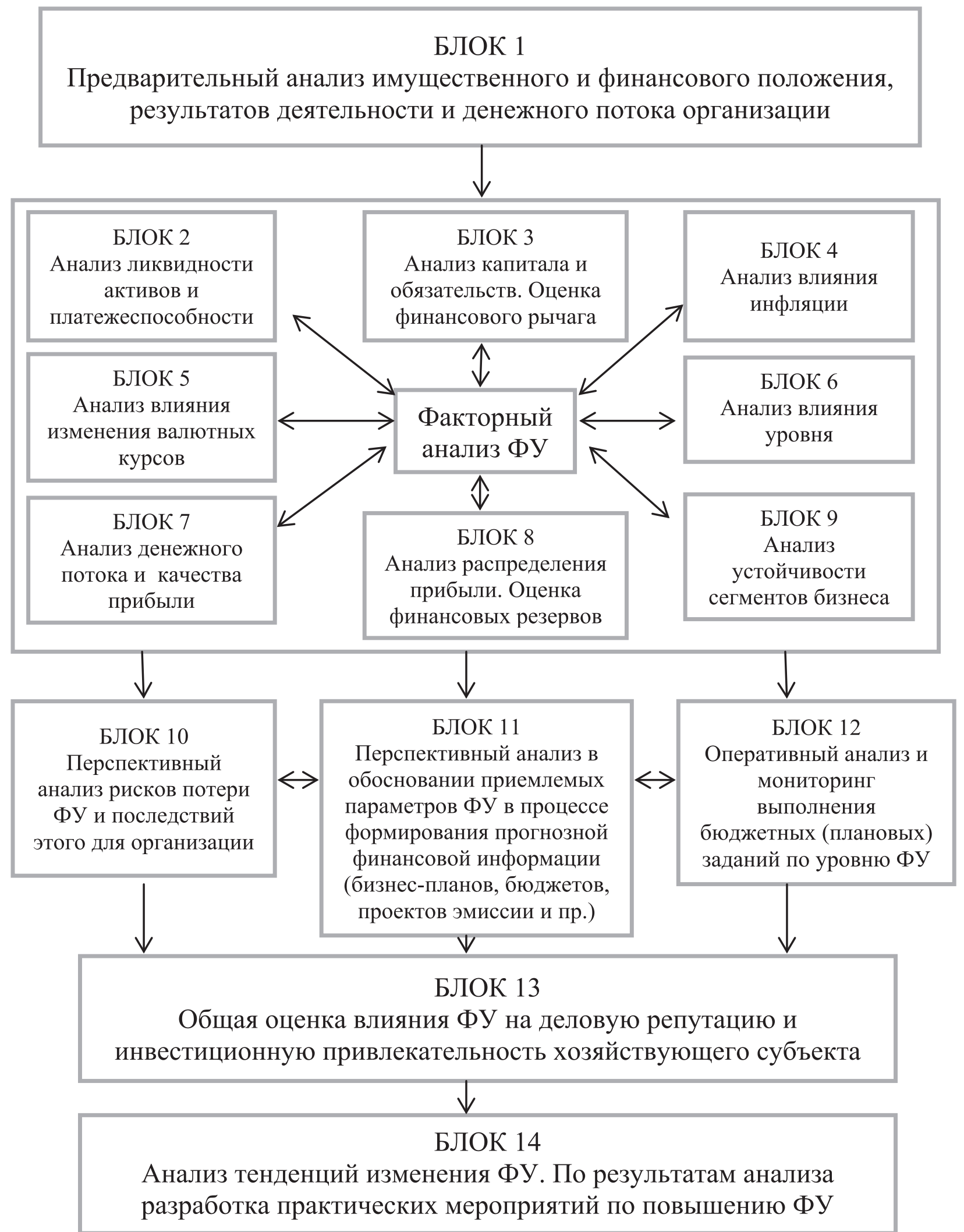

Рис. 1. Схема комплексного анализа финансовой устойчивости организации Все права принадлежат издательству (C) NOTA BENE (OOO «НБ-Медиа») www.nbpublish.com 


\section{Тренды и управление - №1(1)•2013}

Недостатки этого метода:

- $\quad$ разнообразие набора коэффициентов связано с различными источниками информации, используемыми авторами;

- $\quad$ значимость каждого коэффициента зависит от квалификации экспертов;

- коэффициенты, рассчитанные на основе данных бухгалтерской отчетности, отражают ретроспективные данные, что приводит к снижению качества оценки;

- $\quad$ - использование различных методов для рейтинговой оценки приводит к неоднозначным результатам.

Ресурсный подход. Сущность ресурсного подхода заключается в том, что ресурсы рассматриваются как факторы производства, привлекаемые для достижения результата. Различают трудовые, материальные, финансовые, информационные, интеллектуальные ресурсы и пр. Их наличие, состав и эффективность использования определяют объем продаж (выручку), прибыль, себестоимость

Как правило, при оценке и прогнозировании развития организации не имеет смысла использовать большое число показателей. Показатели могут быть из различных по экономическому содержанию и назначению групп, но их назна- чение - характеристика типа «экономическое развитие производства» в соответствии со структурой и динамикой показателей, характеризующих использование ресурсов ${ }^{8}$.

Различные сочетания динамики объема продаж (производства), потребляемых ресурсов и величины их отдачи определяют тип экономического развития производства и идентифицируют показатели, характеризующие финансовую устойчивость организации.

При оценке финансовой устойчивости организации актуальным является вопрос о времени ухудшения финансового состояния предприятия. В рамках рассматриваемого подхода таким моментом будет наличие экстенсивных факторов в развитии производства. Наличие экстенсивных факторов свидетельствует об имеющихся резервах, использование которых может вывести организацию из наступающей кризисной ситуации 9

Анализ существующих и исследование новых систем показывает, что для обеспечения системной и структурной устойчивости сложных систем производства, экономики, живописи, музыки и других областей необходимо установить между основными показателями системы соотношения, соответствующие принципу «золотой пропорции» (таблица 1$)^{10}$.

Таблица 1

Классификация финансовой устойчивости с учетом принщипа «золотой пропоричии» в зависимости от типа экономического развития производства

\begin{tabular}{|l|l|l|}
\hline Вид финансовой устойчивости & \multicolumn{1}{|c|}{ Тип развития производства } & $\begin{array}{c}\text { Границы } \\
\text { измерения }\end{array}$ \\
\hline Абсолютная & Интенсивный & Более $62 \%$ \\
\hline
\end{tabular}

${ }^{8}$ Петухов, Р.М. Оценка эффективности промышленного производства: методы и показатели / Р.М. Петухов. - М.: Экономика, 1990. - 191 с.

9 Любушин, Н.П. Анализ методов и моделей оценки финансовой устойчивости организаций / Н.П. Любушин // Экономический анализ: теория и практика. -2010. - №1. - С. 3-11.

${ }^{10}$ Прангишвили, И.В. Системный подход и повышение эффективности управления / И.В. Прангишвили. - М.:

Наука, 2005. - 421 c.

\footnotetext{
7 Любушин, Н.П. Анализ методов и моделей оценки финансовой устойчивости организаций / Н.П. Любушин // Экономический анализ: теория и практика. - 2010. №1. - C. 3-11.
} 
Управление предприятием

\begin{tabular}{|l|l|l|}
\hline Нормальная & Интенсивно-экстенсивный & От 38\% до 62\% \\
\hline $\begin{array}{l}\text { Неустойчивое финансовое } \\
\text { состояние }\end{array}$ & Экстенсивно-интенсивный & От 14\% до 38\% \\
\hline $\begin{array}{l}\text { Кризисное финансовое } \\
\text { состояние }\end{array}$ & Экстенсивный & Менее 14\% \\
\hline
\end{tabular}

Ресурсно-управленческий подход. Эффективность используемых ресурсов зависит от качества управления организацией, что не учитывается в приведенных способах оценки устойчивости. Плохой менеджмент в организации может привести к кризисной ситуации. В связи с этим наращивание экономического потенциала следует дополнить следующим условием: темп роста управленческих расходов на объем выпуска продукции не должен превышать темп роста удельного расхода ресурсов для выпуска этого же объема продукции:

$$
\text { при } \frac{\mathrm{d} \mathrm{S}^{\mathrm{I}}}{\mathrm{dt}} \leqslant \frac{\mathrm{d} \mathrm{S}^{\Pi p}}{\mathrm{dt}}
$$

$$
\begin{aligned}
& \text { где } \frac{\mathrm{dS} \text { Упр }}{\mathrm{dt}}-\text { темп роста управленческих } \\
& \text { расходов; } \\
& \frac{\mathrm{dS} \mathrm{mp}}{\mathrm{dt}} \text {-темп роста прямых затрат на ресурсы. }
\end{aligned}
$$

Рейтинговая оценка финансовой устойчивости организаций по периодам исследования определяется в соответствии с алгоритмами. Значимость показателей может изменяться под воздействием внешних условий функционирования организации ${ }^{11}$.

Методы и модели, основанные на стохастическом анализе. Выводы о вероятности потери финансовой устойчивости можно

\footnotetext{
11 Любушин, Н.П. Анализ методов и моделей оценки финансовой устойчивости организаций / Н.П. Любушин // Экономический анализ: теория и практика. - 2010. №1. - C. 3-11.
}

делать на основе сопоставления показателей данной и аналогичных организаций, обанкротившихся или избежавших банкротства. Однако в России найти в каждом случае подходящий аналог для сравнения весьма затруднительно, а часто и невозможно. Надежность выводов о возможности потери финансовой устойчивости существенно повышается, если дополнить финансовый анализ прогнозированием вероятности потери финансовой устойчивости организации с использованием методов многофакторного стохастического анализа ${ }^{12}$.

Методические подходы к построению многофакторных моделей прогнозирования банкротства могут использоваться при прогнозировании финансовой устойчивости российских организаций. Для достижения более высокой точности результатов необходимо постоянно корректировать набор показателей и значения коэффициентов весового влияния каждого показателя с учетом вида экономической деятельности и других перечисленных условий ${ }^{13}$.

Методы и модели, основанные на теории нечетких множеств. Нечеткая логика является одной из наиболее успешных со-

\footnotetext{
12 Любушин, Н.П. Экономический анализ: учебное пособие для студентов вузов, обучающихся по специальности 080109 «Бухгалтерский учет, анализ и аудит» и 080105 «Финансы и кредит» / Н.П. Любушин. - М.: ЮНИТИДАНА, 2007. - 423 c.

13 Любушин, Н.П. Использование зарубежного опыта в комплексной оценке финансового положения организации для антикризисного управления / Н.П. Любушин // Экономический анализ: теория и практика. - 2004. №11. - С. 7-10.
} 


\section{Тренды и управление - №1(1)•2013}

временных технологий для разработки и оценки сложных систем управления организацией. Она заполняет важный промежуток в методах проектирования незатронутыми математическими подходами (например, проект линейного управления) и логическими подходами (например, экспертными системами) в проектировании и оценке эффективности систем ${ }^{14}$.

Сравнительный анализ различных подходов к оценке финансовой устойчивости предприятия в условиях нестабильности российской экономики свидетельствует, что она должна иметь комплексный характер, т.к. устойчивость предприятия необходимо оценивать, используя систему показателей, применяемых в рамках всех рассмотренных подходов.

Оценка финансовой устойчивости предприятия является важнейшей стадией управленческого цикла и элементом финансового менеджмента. Она обеспечивает своевременное поступление необходимой информации и является основой принятия управленческих решений. Данная оценка выполняет две основные функции: информационную и аналитическую, связанные с разработкой и обоснованием управленческих решений. Информация о финансовой деятельности предприятия является предметом труда длительного многократного пользования; она способна к саморазвитию; ее количественное накопление дает возможность на основе анализа информации выявлять связи между отдельными элементами хозяйственного механизма предприятия. В процессе управления финансовой устойчивостью предприятия финансовая информация преобразуется в управляющие решения, регламентирующие

\footnotetext{
14 Любушин, Н.П. Анализ методов и моделей оценки финансовой устойчивости организаций / Н.П. Любушин // Экономический анализ: теория и практика. - 2010. №1. - C. 3-11.
}

перевод управляемого объекта из фактического состояния в желаемое. Направленность оценки финансовой устойчивости предприятия на конечные результаты деятельности требует увязки показателей оценки устойчивости предприятия с показателями, характеризующими возможность его стабильного экономического развития.

Задачи предприятия, решаемые с помощью оиенки ФУ:

1. Управление финансовой устойчивостью предприятия должно решать задачи выявления ее отклонений от определенных (нормативных) ее значений с учетом достижения целей его производственнохозяйственной деятельности и дальнейшего развития. При этом указанные цели должны разрабатываться многовариантно и уточняться с изменением условий деятельности предприятия.

2. При системном подходе оценка финансовой устойчивости предприятия становится важнейшим инструментом обоснования целей его развития, обеспечивающим стабильное функционирование предприятия и повышение эффективности его деятельности ${ }^{15}$.

3. Оценка финансовой устойчивости предприятия должна давать развернутую характеристику его финансового состояния с точки зрения обеспеченности предприятия финансовыми ресурсами. Кроме того, она должна характеризовать состояние предприятия и с позиции анализа качества результатов его финансовой деятельности.

4. Анализ финансовой устойчивости предприятия обеспечивает оценку эффек-

\footnotetext{
${ }^{15}$ Авдонин Б.Н., Батьковский А.М., Булава И.В. и др. Финансовое оздоровление и развитие предприятий радиоэлектронного комплекса в период посткризисного восстановления и модернизации российской экономики / Под ред. Авдонина Б.Н. - М.: Креативная экономика, 2010. -472 c.
} 
тивности использования финансовых ресурсов, определяя дефицит или избыток ресурсов, потребность в их увеличении или росте качества их использования. Это позволяет давать объективную оценку результативности деятельности предприятия. В этом случае данная оценка выступает в качестве средства контроля деятельности предприятия.

5. Оценка финансовой устойчивости позволяет решать следующие важнейшие задачи: обнаружение скрытых резервов и разработка вариантов их мобилизации; обоснование вариантов стратегического развития предприятия.

6. Наиболее сложная задача анализа финансовой устойчивости предприятия - это разработка мер воздействия на финансовые процессы с целью приближения их к оптимальному состоянию.

Решение вышеперечисленных задач направлено на повышение эффективности управленческих воздействий с целью обеспечения на этой основе устойчивого развития предприятия. Иногда комплексную оценку финансовой устойчивости предприятия можно получить путем суммирования соответствующих аналитических показателей, характеризующих деятельность его подразделений. Однако, чтобы правильно оценить все взаимосвязи элементов предприятия и видов его деятельности, необходим определенный порядок использования этих оценок как основы реализации взаимодействия элементов финансовой устойчивости. При этом следует учитывать, что сумма данных элементов не представляет собой простого целого, так как система всегда многообразнее составляющих ее элементов. Поэтому выводы, сделанные путем разделения финансовой системы предприятия на отдельные ее элементы и их анализа, должны учитывать взаимосвязи данных элементов.
Совершенствование методов оценки финансовой устойчивости промышленного предприятия требует определение путей мобилизации резервов и возможность повышения обоснованности принимаемых финансовых решений в долгосрочном периоде. Для этого необходимо установить тенденции и предпочтительные направления развития предприятия, соответствующие требованиям экономических законов и задачам, а также его возможностям.

Многие предприятия разрабатывают стратегии своего развития в условиях нестабильности. При этом они используют методы стратегического анализа при решении стоящих перед предприятиями задач и определении наиболее экономичных вариантов достижения своих целей при ограниченных финансовых ресурсах, учет использования которых осуществляется в процессе анализа их финансовой устойчивости.

В условиях нестабильности российской экономики успешное функционирование предприятий отражает их финансовую состоятельность: с одной стороны, они все в большей степени должны ориентироваться на потребности потребителей продукции, а с другой, - постоянно повышать антикризисную результативность своей деятельности. Для того чтобы совместить эти два требования, необходима настройка всех элементов механизма анализа финансовой устойчивости предприятия на повышение его действенности, так как показатели ее оценки позволяют установить, как обеспечивается финансовая состоятельность и насколько эффективно осуществляется управление предприятием. При этом возможны следующие основные варианты сочетания относительных и абсолютных показателей оценки финансовой устойчивости предприятия (табл. 2): 
Сочетания показателей оченки финансовой устойчивости предприятия

\begin{tabular}{|c|c|c|}
\hline \multirow{2}{*}{$\begin{array}{c}\text { Варианты сочетания } \\
\text { показателей }\end{array}$} & \multicolumn{2}{|c|}{ Показатели финансовой устойчивости } \\
\cline { 2 - 3 } & Абсолютные & Относительные \\
\hline 1 & Растут & Не меняются \\
\hline 2 & Не меняются & Снижаются \\
\hline 3 & Растут & Снижаются \\
\hline 4 & Растут & Растут \\
\hline 5 & Снижаются & Растут \\
\hline
\end{tabular}

Исследование темпов изменения показателей для каждой из приведенных ситуаций позволяет оценивать и контролировать уровень финансовой устойчивости предприятия. При этом с целью предварительной оценки финансового состояния предприятия используются, как правило, показатели двух классов. Первый включает показатели ликвидности и финансовой устойчивости, второй - показатели интенсивности использования ресурсов и деловой активности предприятия. Однако указанные показатели не охватывают всех аспектов финансовой устойчивости предприятия и не характеризуют степень достижения его целей с точки зрения состоятельности предприятия. По нашему мнению, наряду с ними целесообразно использовать для достижения указанной цели показатели, характеризующие соотношение заемных и собственных средств; коэффициент обеспеченности собственными средствами; коэффициент маневренности собственных и оборотных средств. Они входят в класс нормированных показателей, так как их снижение ниже нормативных значений или их превышение над нормативными значениями означает ухудшение финансового состояния анализируемого предприятия.

Действующая методология оценки финансовой устойчивости предприятия показывает, что необходимо ее дальнейшее развитие, в первую очередь, путем совершенствования методов оценки, позволяющих анализировать эффективность использования его ресурсов. При этом следует иметь в виду, что финансовая устойчивость предприятия проявляется через финансовые отношения и выражается финансовыми ресурсами. Финансовая устойчивость в этом смысле представляется сложной комбинацией финансового равновесия и роста ценности капитала, которая обеспечивается рациональным использованием технических, материальных, людских ресурсов. Поэтому оценка финансовой устойчивости промышленного предприятия должна заключаться не только в расчете соответствующих показателей и взаимосвязей между ними, но и обязательно включать анализ процесса управления финансовой устойчивостью, так как повышение его эффективности оказывает непосредственное и существенное влияние на уровень устойчивости. В условиях нестабильности российской экономики повышение эффективности управления финансовой устойчивостью предприятия становится особенно важным фактором ее роста.

В условиях нестабильности должны быть также усилены функциональная направленность оценки финансовой устойчивости предприятия и ее перспективный характер. Это превратит анализ финансовой устойчивости предприятия в действенный инструмент обоснования управленческих ре- 
шений, а сама оценка получит более четкую направленность и конструктивный характер, так как будет непосредственно увязан с обеспечением экономической эффективности деятельности предприятия и разработкой стратегий его развития.

Оценивая финансовое состояние промышленного предприятия и возможности его оздоровления с целью активизации его инновационной деятельности, необходимо анализировать как коэффициенты текущей ликвидности и обеспеченности собственными средствами, так и такие показатели как: темпы изменения объема произведенной продукции; прибыль (убыток) предприятий; коэффициенты выбытия, ввода в действие и обновления основных производственных фондов; изменение численности промышленно-производственного персонала, в том числе инженерно-технических работников; доля отгруженной продукции в объеме произведенной продукции; удельный вес экспортной продукции в общем объеме отгруженной продукции; удельный вес сертифицированной продукции; удельный вес расходов на НИОКР в общих затратах на производство и реализацию продукции; использование кредитов и др. Выводы о возможности проведения санации собственными средствами, можно делать только после проведения комплексного и системного анализа этих показателей. Наиболее целесообразно установить критерии оценки на основе изучения структуры текущих активов предприятий и определения их средних значений ${ }^{16}$. Несмотря на то, что этот процесс трудоемок, он основан на реальных данных, учитывающих условия нестабильности российской экономики.

В целом, обобщая рассмотренные предложения по совершенствованию анализа фи-

\footnotetext{
${ }^{16}$ Батьковский А.М. Управление инновационным развитием предприятий радиоэлектронной промышленности. - М.: онтоПринт, 2010. - 248 с.
}

нансовой устойчивости предприятий, можно сделать вывод, что их реализация позволяет повысить эффективность их деятельности.

\section{Библиография:}

1. Авдонин Б.Н., Батьковский А.М., Булава И.В. и др. Финансовое оздоровление и развитие предприятий радиоэлектронного комплекса в период посткризисного восстановления и модернизации российской экономики / Под ред. Авдонина Б.Н. - М.: Креативная экономика, 2010. - 472 с.

2. Аверина, О.И. Анализ финансовой устойчивости предприятия по принципам РСБУ и МСФО / О.И. Аверина, И.С. Мамоева // Экономический анализ: теория и практика. - 2009. - №34. - С. 36-44.

3. Ахметзянова, Д.Г. Влияние некоторых элементов учетной политики на показатели финансовой устойчивости хозяйствующего субъекта / Д.Г. Ахметзянова // Экономический вестник РТ. - 2009. - №2. - С. 28-31.

4. Батьковский А.М. Методологические проблемы совершенствования анализа финансовой устойчивости предприятия радиоэлектронной промышленности // Экономика, предпринимательство и право. — 2011. — № 1 (1). — с. 30-44.

5. Батьковский А.М. Управление инновационным развитием предприятий радиоэлектронной промышленности. - М.: онтоПринт, 2010. - 248 с.

6. Бернстайн, Л.А. Анализ финансовой отчетности / Л.А. Бернстайн. - М.: Финансы и статистика, 2002. - 444 с.

7. Ендовицкий, Д.А. Системный подход к анализу финансовой устойчивости коммерческой организации / Д.А. Ендовицкий // Экономический анализ: теория и практика. - 2005. - №6. - С. 7-13. 


\section{Тренды и управление - №1(1)• 2013}

8. Любушин, Н.П. Анализ методов и моделей оценки финансовой устойчивости организаций / Н.П. Любушин // Экономический анализ: теория и практика. - 2010. - №1. - C. 3-11.

9. Любушин, Н.П. Использование зарубежного опыта в комплексной оценке финансового положения организации для антикризисного управления / Н.П. Любушин // Экономический анализ: теория и практика. - 2004. - №11. - С. 7-10.

10. Любушин, Н.П. Экономический анализ: учебное пособие для студентов вузов, обучающихся по специальности 080109 «Бухгалтерский учет, анализ и аудит» и 080105 «Финансы и кредит» / Н.П. Любушин. - М.: ЮНИТИ-ДАНА, 2007. - 423 с.

11. Миндлин, Ю.Б. Составляющие оценки эффективности системы управления предприятием в экономике региона / Ю.Б. Миндлин - М.: Микроэкономика. - 2008г. - №7. - С. 90-96

12. Петухов, Р.М. Оценка эффективности промышленного производства: методы и показатели / Р.М. Петухов. - М.: Экономика, 1990. - 191 c.

13. Прангишвили, И.В. Системный подход и повышение эффективности управления / И.В. Прангишвили. - М.: Наука, 2005. $421 \mathrm{c}$.

\section{References (transliteration):}

1. Avdonin B.N., Bat'kovskiy A.M., Bulava I.V. i dr. Finansovoe ozdorovlenie i razvitie predpriyatiy radioelektronnogo kompleksa v period postkrizisnogo vosstanovleniya i modernizatsii rossiyskoy ekonomiki / Pod red. Avdonina B.N. - M.: Kreativnaya ekonomika, 2010. - $472 \mathrm{~s}$.

2. Averina, O.I. Analiz finansovoy ustoychivosti predpriyatiya po printsipam RSBU i MSFO / O.I. Averina, I.S. Mamoeva // Ekonomicheskiy analiz: teoriya i praktika. - 2009. - №34. - S. 36-44.

3. Akhmetzyanova, D.G. Vliyanie nekotorykh elementov uchetnoy politiki na pokazateli finansovoy ustoychivosti khozyaystvuyushchego sub'ekta / D.G. Akhmetzyanova // Ekonomicheskiy vestnik RT. - 2009. - №2. - S. 28-31.

4. Bat'kovskiy A.M. Metodologicheskie problemy sovershenstvovaniya analiza finansovoy ustoychivosti predpriyatiya radioelektronnoy promyshlennosti // Ekonomika, predprinimatel'stvo i pravo. — 2011. — № 1 (1). - c. 30-44.

5. Bat'kovskiy A.M. Upravlenie innovatsionnym razvitiem predpriyatiy radioelektronnoy promyshlennosti. - M.: ontoPrint, 2010. - 248 s.

6. Bernstayn, L.A. Analiz finansovoy otchetnosti / L.A. Bernstayn. - M.: Finansy i statistika, 2002. - 444 s.

7. Endovitskiy, D.A. Sistemnyy podkhod k analizu finansovoy ustoychivosti kommercheskoy organizatsii / D.A. Endovitskiy // Ekonomicheskiy analiz: teoriya i praktika. -2005. - №6. - S. 7-13.

8. Lyubushin, N.P. Analiz metodov i modeley otsenki finansovoy ustoychivosti organizatsiy / N.P. Lyubushin // Ekonomicheskiy analiz: teoriya i praktika. - 2010. - №1. - S. 3-11.

9. Lyubushin, N.P. Ispol'zovanie zarubezhnogo opyta $\mathrm{v}$ kompleksnoy otsenke finansovogo polozheniya organizatsii dlya antikrizisnogo upravleniya / N.P. Lyubushin // Ekonomicheskiy analiz: teoriya i praktika. -2004. - №11.-S. 7-10.

10. Lyubushin, N.P. Ekonomicheskiy analiz: uchebnoe posobie dlya studentov vuzov, obuchayushchikhsya po spetsial'nosti 080109 «Bukhgalterskiy uchet, analiz i audit» 080105 «Finansy i kredit» / N.P. Lyubushin. - M.: YuNITI-DANA, 2007. - $423 \mathrm{~s}$.

11. Mindlin, Yu.B. Sostavlyayushchie otsenki effektivnosti sistemy upravleniya predpriyatiem v ekonomike regiona / Yu.B. Mindlin - M.: Mikroekonomika. -2008g. - №7. -S. 90-96 
Управление предприятием

12. Petukhov, R.M. Otsenka effektivnosti promyshlennogo proizvodstva: metody i pokazateli / R.M. Petukhov. - M.: Ekonomika, 1990. - $191 \mathrm{~s}$.
13. Prangishvili, I.V. Sistemnyy podkhod i povyshenie effektivnosti upravleniya / I.V. Prangishvili. - M.: Nauka, 2005. $-421 \mathrm{~s}$. 